Volume $4 \cdot$ Nomor $1 \cdot$ Oktober 2020

Pege (Hal.) : $133-142$

(C) Universitas Pamulang

JL.Surya Kencana No.1 Pamulang, Tangerang Selatan - Banten

website. :

Telp. (021) 7412566, Fax (021) 7412491

http://www.openjournal.unpam.ac.id/index.php/JPK

Email :jurnalmarketing.unpam@gmail.com

\title{
Marketplace Shopee Sebagai Media Promosi Penjualan Umkm di Kota Blitar
}

\author{
Eka Septiana Sulistiyawati ${ }^{1}$. Anna Widayani ${ }^{2}$ \\ ${ }^{12}$ Akademi Komunitas Negeri Putra Sang Fajar Blitar, Email :annawidayani@akb.ac.id
}

\begin{abstract}
Abstrak. Marketplace Shopee merupakan salah satu marketplace yang sedang berkembang di Indonesia. Marketplace Shopee saat ini dimanfaatkan oleh Usaha Mikro Kecil dan Menengah (UMKM) untuk promosi penjualan. Di kota Blitar sendiri UMKM yang sudah memanfaatkan Shopee sebagai media promosi penjualan yaitu UMKM Sambel Pecel dan Bumbu Gado-Gado Kuncit Kota Blitar. Penelitian ini merupakan penelitian deskrptif kualitatif. Teknik analisis data yang digunakan adalah reduksi, pemaparan data dan penarikan kesimpulan. Penelitian yang dilakukan bahwa marketplace Shopee sebagai media promosi penjualan d UMKM Sambel Pecel dan Bumbu GadoGado Kuncit Kota Blitar masih belum maksimal. Marketplace Shopee sebagai media promosi penjualan di UMKM Sambel Pecel dan Bumbu Gado-Gado Kuncit Kota Blitar harus lebih ditingkatkan lagi agar admin dapat melayani para konsumen dengan lebih maksimal agar daya beli konsumen meningkat.
\end{abstract}

Kata Kunci: Promosi; Marketplace Shopee; UMKM.

Abstract. The Shopee marketplace is one of the growing marketplaces in Indonesia. The Shopee marketplace is currently being used by Micro, Small, and Medium Enterprises (MSMEs) for sales promotion. In the city of Blitar itself, the MSMEs that have used Shopee as a sales promotion media are MSME Sambel Pecel and Bumbu Gado-Gado Kuncit in Blitar. This research is a qualitative descriptive study. The data analysis techniques used were reduction, data exposure, and conclusion drawing. Research conducted shows that the Shopee marketplace as a sales promotion media for SMEs Sambel Pecel and Bumbu Gado-Gado Kuncit In Blitar is still not optimal. The Shopee marketplace as a sales promotion at MSMEs Sambel Pecel and Bumbu Gado-Gado Kuncit must be further improved so that admins can serve consumers more optimally so that consumer purchasing power increases.

Keywords: Promotion; Marketplace Shopee; MSMEs. 


\section{A. PENDAHULUAN}

Saat ini perkembangan teknologi semakin pesat yang ditandai dengan munculnya internet. Internet memiliki manfaat yang sangat beragam dari beberapa aspek. Salah satu kegunaan internet adalah untuk proses menjual dan membeli secara online, yang lebih dikenal dengan sebutan e-Commerce. Pada Undang Undang No. 11 tahun 2008 tertuang kebijakan pemerintah bahwa manfaat teknologi informasi dan transaksi secara elektronik dilaksanakan berdasarkan atas kehati-hatian, kepastian hukum, dan kebebasan dalam memilih bahkan menggunakan teknologli (Indonesia, 2008). Adapun tujuan dalam melaksanakan transaksi secara online salah satunya adalah untuk meningkatkan perdagangan dan perekonomian secara nasional.

Hasil dari survey Asosiasi Penyelenggara Jasa Internet (APJII, 2019) yang menyatakan bahwa pengguna internet di Indonesia mengalami peningkatan setiap tahunnya. (APJII, 2019) rutin melakukan survey dan perilaku internet setiap tahun. Tujuannya untuk mengetahui perkembangan internet di Indonesia dan mendapatkan gambaran perilaku warganet saat mengakses internet.

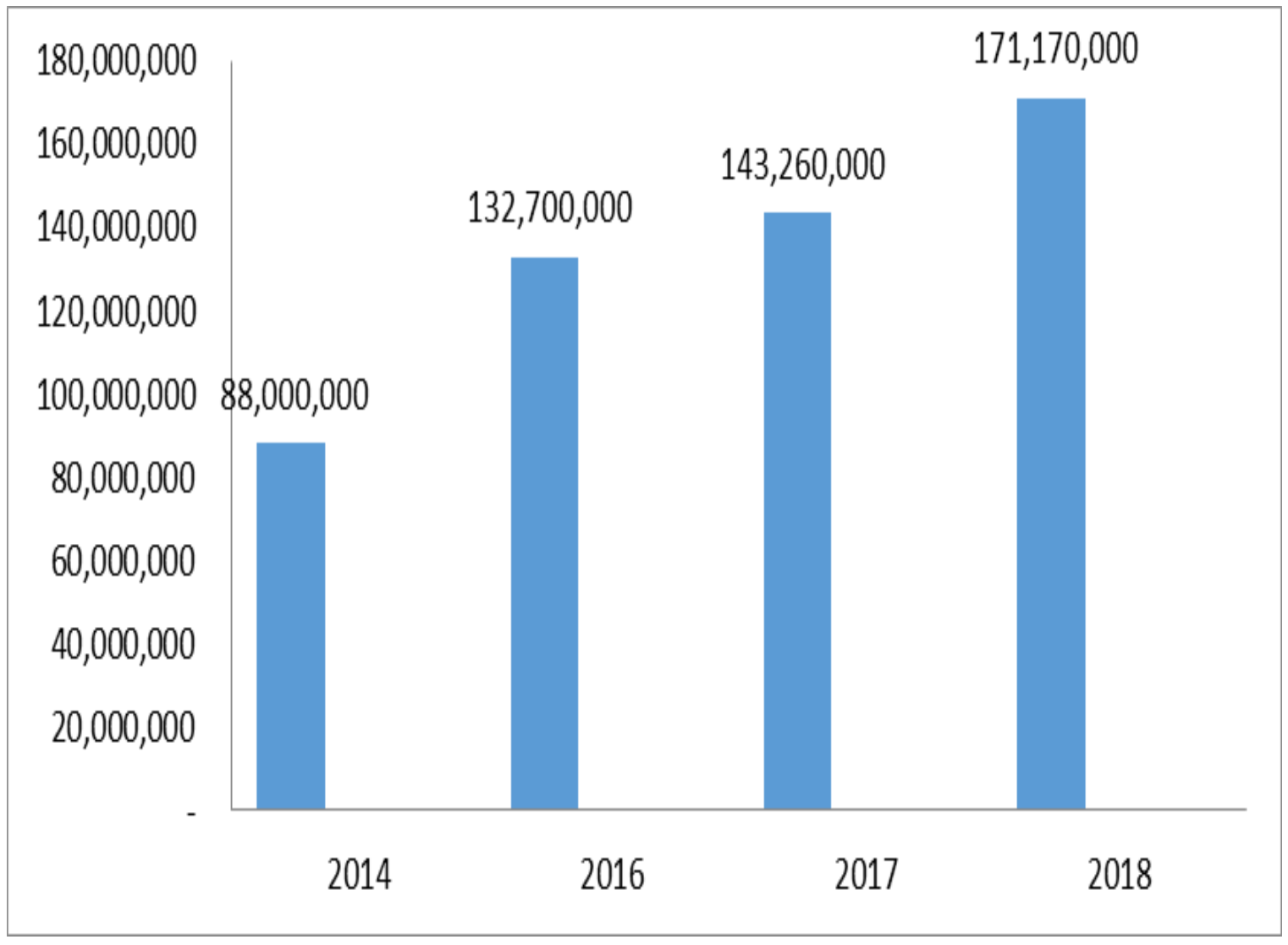

Sumber: APJII, 2019

Gambar 1.1 Pengguna Internet 
Berdasarkan gambar 1.1 survey APJII pada tahun 2019 tentang pengguna internet di Indonesia. Pada tahun 2014 pengguna inernet d Indonesia mencapai 88 juta orang. Namun, pada tahun 2016 ada kenaikan pada pengguna internet menjadi 132,7 juta. Kemudian, pada tahun 2017 jumlahnya semakin meningkat berjumlah 143,26 juta. Angka ini terus meningkat sampai tahun 2018 mencapai 171,17 juta pengguna internet.

Media promosi penjualan dengan menggunakan teknologi Internet yang sering digunakan yang lebih dikenal dengan sebutan e-commerce. E-commerce merupakan sebuah aplikasi yang digunakan untuk melakukan segala aktivitas kegiatan jual-beli secara online. Selain itu, e-commerce juga dapat memasarkan, mempromosikan, sedangkan untuk pembayaran pembelian dapat dilakukan melalui transfer bank, dan untuk pengiriman produk dilakukan dengan menggunakan jasa kirim seperti JNE, JNT dan lainnya. Saat ini E-commerce berkembang pesat, karena hampir semua kebutuhan dapat di jual-belikan di platform tersebut. Negara yang menggunakan E-commerce untuk kegiatan jual beli salah satunya adalah Indonesia, hal ini dapat diketahui dengan maraknya situs jual beli secara online yang mulai bermunculan, seperti Tokopedia, Lazada, Blibli, Bukalapak, Shopee dan masih banyak lainnya.

Shopee merupakan salah satu marketplace yang pertama kali dijalankan oleh Garena yang saat ini berubah nama menjadi SEA Group. Garena sendiri mengusung mobile marketplace Bisnis C2C (customer to customer). Pada Desember 2015 shopee resmi diperkenalkan di Indonesia di bawah naungan PT Shopee International Indonesia. Produk yang ditawarkan di marketplace Shopee banyak variasinya, antara lain produk Kecantikan, Pakaian Pria, Pakaian Wanita, Handphone \& Accesories, Komputer \& Accesories, Perlengkapan Rumah, Elektronik, Makanan \& Minuman, Pulsa, Tagihan \& Tiket, Fashion Muslim, Fashion Bayi \& Anak, Ibu \& Bayi, Tas Pria \& Wanita, Kesehatan, Fotografi, Olahraga, Voucher, Buku \& Alat Tulis, Serba Serbi, Sepatu Wanita \& Pria, Souvenir \& Pesta, Jam Tangan, Hobi \& Koleksi, dan masih banyak lagi.

Shopee yang merupakan marketplace yang digunakan oleh para penjual online di Indonesia. Pada tahun 2015 shopee pertama kali ada di Indonesia dan menjadi situs penjualan online yang paling diminati oleh masyarakat (Bachdar, 2018). Namun saat pertama kali marketplace Shopee masuk di Indonesia, marketplace ini kalah saing dengan marketplace yang sudah berkembang terlebih dahulu seperti Tokopedia dan Lazada. Tetapi pada tahun-tahun terakhir jumlah download aplikasi dan terpopuler yang memegang rating tertinggi adalah marketplace Shopee (katadata.co.id).

Tabel 1.1 Total Pesanan Shopee

\begin{tabular}{|c|c|c|c|}
\hline o. & Tahun & Pesanan & Pembeli Aktif \\
\hline 1 & 2017 & 244,8 juta & 21,7 juta \\
\hline 2 & 2018 & 604,5 juta & 49,9 juta \\
\hline
\end{tabular}

Sumber: Bisnis.com, 2019 
Dari tabel 1.1 dapat dilihat bahwa marketplace Shopee tercatat telah melayani hingga 244,8 juta pesanan pada 2017 dan mengalami peningkatan pada tahun 2018 sebanyak 604,5 juta pesanan. Berdasarkan data di atas sebanyak 206,9 juta pesanan dihasilkan pada tahun 2018, sedangkan pada tahun 2017 sebanyak 98,3 juta pesanan. Jumlah pembeli yang aktif di shopee tercatat sebanyak 49,9 juta orang di sepanjang tahun 2018, sedangkan dari tahun 2017 sebesar 21,7 juta pembeli aktif, sehingga penjual yang aktif mengalami peningkatan.

Marketplace Shopee saat ini dimanfaatkan oleh Usaha Mikro Kecil dan Menengah (UMKM). (Latifah, 2020) aplikasi E-commerce memberikan kepercayaan dalam bentuk jaminan dan memberikan kemudahan dalam bertransaksi dan serta penilaian dan rekomendasi dari pelanggan menjadi bentuk support dan layanan pada marketplace shopee dalam upaya meyakinkan kepercayaan para penggunanya di Indonesia saat ini. Dengan semakin pesatnya perkembangan teknologi informasi, pelaku UMKM sudah menyadari bahwa pada era saat ini konsumen lebih suka berbelanja secara online, hal tersebut dikarenakan kecenderungan para konsumen untuk mengikuti perkembangan zaman. Pelaku UMKM harus menyiapkan segala strategi untuk menghadapi perkembangan saat ini, salah satu usaha yang perlu dilakukan adalah dengan menawarkan produk menggunakan e-commerce. Setiap pelaku UMKM saat ini harus mengikuti perkembangan teknologi agar produk yang mereka tawarkan tidak kalah saing dengan produk luar. Kesiapan pelaku industri kecil dan menengah terutama pengetahuan, keterampilan, dan pemanfaatan teknologi, dalam era digital saat ini sangat dibutuhkan (Widayani, 2020). Oleh kerena itu, para pelaku UMKM harus siap untuk menawarkan produk melalui perkembangan teknologi yang semakin maju.

\section{B. KAJIAN LITERATUR}

Pada Penelitian ini terdapat beberapa variabel penelitian, antara lain pemasaran, promosi, e-commerce, dan marketplace shopee.

Pemasaran merupakan proses sosial manajerial seseorang atau kelompok untuk mendapatkan apa yang diinginkan dan dibutuhkan melalui penciptaan dan pertukaran produk dan lain (Usmara, 2008). Pemasaran merupakan suatu sistem secara keseluruhan dari suatu kegiatan usaha yang dilakukan dalam mengonsep, menentukan suatu harga, memperkenalkan produk dan menyalurkan barang dan jasa yang dapat memuaskan kebutuhan pembeli potensial maupun pembeli yang ada William dalam (Usmara, 2008). American Marketing Association yang dikutip oleh (Assauri, 2013) pemasaran merupakan hasil dari suatu prestasi kerja dalam menjalankan suatu kegiatan usaha yang berkaitan dengan perpindahan barang dan jasa dari produsen sampai ke konsumen.

Promosi merupakan sebuah komunikasi yang memberikan penjelasan dan meyakinkan calon konsumen mengenai barang dan atau jasa dengan tujuan untuk mendapatkan perhatian, mendidik, mengingatkan dan meyakinkan para calon konsumen (Buchari, 2006). Sedangkan menurut (Kotler, 2006.) Promosi penjualan sebagai unsur utama dalam menjalankan pemasaran dengan berbagai alat insentif yang sebagian besar berjangka pendek, dengan dirancang untuk merangsang pembeli dalam pembelian produk ataupun jasa tertentu dengan lebih cepat dan lebih besar yang dilakukan oleh konsumen atau pedagang. Promosi merupakan salah satu variabel yang terdapat pada bauran pemasaran yang yang berfungsi sebagai alat komunikasi perusahaan dengan konsumen, dan sebagai alat untuk mempengaruhi konsumen untuk melakukan pembelian pada produk atau penggunaan jasa (Lupiyoadi dan Hamdani, 2006).

E-commerce merupakan singkatan dari Electronic Commerce yang artinya suatu sistem pemasaran yang memanfaatkan internet dan media elektronik. E-commerce ini 
dapat mencakup beberapa kegiatan diantaranya marketing, penjualan, pembelian, distribusi dari sebuah produk yang dilakukan dengan memanfaatkan sistem elektronik seperti Internet atau jaringan komputer yang lain (Rahmati, 2009). Mekanisme teknologi tersebut dapat dioperasikan di mana saja oleh semua negara di dunia karena sudah mempunyai standar yang bersifat universal (Kwahk \& Ge, 2012). E-commerce merupakan bagian dari bisnis elektronik yang memiliki cakupan e-business yang lebih luas, tidak hanya sekedar bidang perniagaan tetapi juga mencakup pengkolaborasian mitra bisnis, pelayanan pada nasabah, lowongan pekerjaan dan lain-lain (Siregar, 2010). E-commerce juga dapat melakukan pertukaran data secara elektronik, transfer dana elektronik, sistem manajemen inventori dan sistem pengumpulan data secara otomatis (Sutrisno, 2011). Suatu bentuk dari kemajuan teknologi informasi ( $\mathrm{TI}$ ) yang telah membawa sejumlah perubahan, antara lain interaksi yang menjadi lebih mudah karena tanpa adanya batasan waktu dan tempat, melakukan promosi yang lebih mudah, dapat memperluas pangsa pasar, dan adanya transparansi bisnis dan kemudahan dalam memberikan pelayanan kepada pellanggan atau konsumen adalah sistem E-Commerce (Bernadi, 2013).

Shopee merupakan salah satu marketplace yang memanfaatkan peluang bisnis dengan memaksimalkan segmen mobile marketplace karena hal ini dapat mempermudah transaksi jual beli. UMKM juga memiliki keunggulan diantaranya: menghasilkan suatu barang atau jasa yang sangat dekat dengan kebutuhan masyarakat. UMKM juga mampu bergerak dan menyerap tenaga kerja meski jumlahnya terbatas. Selain itu, UMKM juga mempunyai flektabilitas yang tinggi jika dibandingkan dengan usaha yang berkapasitas lebih besar (As'ari, 2008).

\section{METODOLOGI PENELITIAN}

Penelitian ini merupakan penelitian Deskriptif Kualitatif. Objek penelitian pada UMKM Sambel Pecel dan Gado-gado yang ada di Kota Blitar, periode penelitian tanggal 1 September - 30 September 2019. Pengumpulan data yang dipakai dalam penelitian yaitu dengan wawancara kepada pemilik UMKM Sambel Pecel dan Gado-gado yang ada di Kota Blitar.

\section{HASIL DAN PEMBAHASAN}

Media promosi penjualan yang digunakan di UMKM Sambel Pecel dan Bumbu Gado-Gado Kuncit Kota Blitar adalah Shopee. Shopee digunakan mulai dari tahun 2016 sampai sekarang. Namun sebelum menggunakan Shopee UMKM ini juga menggunakan beberapa jenis marketplace yang pada saat itu sedang berkembang di Indonesia, salah satunya marketplace Lazada. Akan tetapi dalam penggunaan marketplace ini mengalami beberapa kendala yang tidak bisa di sebutkan, oleh karena itu pemilik UMKM beralih menggunakan marketplace Shopee sebagai media promosi penjualan karena Shopee merupakan marketplace yang lebih mudah dalam hal operasioanal maupun dalam hal jual produk. Berikut hasil wawancara

"Untuk penggunaan Shopee disini kurang maksimal, karena yang pegang akun Shopee masih kurang bisa memahami selain itu kami juga belum mencari admin baru yang di berikan amanat untuk memegang akun Shopee ini". (NM..38) 
Pemilik UMKM selaku pemegang akun serta bagian di produksi dan keuangan, mengakibatkan pemegang akun lambat dalam merespon pelanggan yang akan melakukan transaksi melalui Shopee.Penjualan selama 1 bulan melalui Shopee diperkirakan tidak lebih dari 10 pack produk. Produk yang sering dibeli konsumen adalah sambel pecel maupun bumbu gado-gado, untuk produk lainnya minat konsumen masih kecil. Meskipun harga yang ditetapkan secara online maupun offline sama, namun konsumen lebih percaya untuk melakukan pembelian secara offline. Berikut adalah tabel penjualan online dan offline yang dilakukan oleh UMKM Sambel Pecel dan Bumbu Gado-Gado Kuncit Kota Blitar selama 7 bulan sebagai berikut:

Tabel 1.2 Penjualan Online selama bulan Juni sampai Desember, 2019

\begin{tabular}{|c|l|c|c|}
\hline No & Bulan & $\begin{array}{c}\text { Jumlah Penjualan Online di } \\
\text { marketplace Shopee (pcs) }\end{array}$ & $\begin{array}{c}\text { Jumlah Penjualan Offline } \\
\text { (pcs) }\end{array}$ \\
\hline 1 & Juni & 16 & 78 \\
\hline 2 & Juli & 9 & 78 \\
\hline 3 & Agustus & 9 & 84 \\
\hline 4 & September & 2 & 54 \\
\hline 5 & Oktober & 3 & 96 \\
\hline 6 & November & 6 & 30 \\
\hline 7 & Desember & 2 & 62 \\
\hline \multicolumn{2}{r|}{ Total } & $\mathbf{4 7}$ & $\mathbf{4 8 2}$ \\
\hline
\end{tabular}

Sumber: data panjualan Sambel Pecel dan Bumbu Gado-Gado Kuncit Kota Blitar, diolah oleh Penulis, 2020

Dari tabel di atas dapat disimpulkan bahwa penjualan meningkat jika menggunakan offline. Total dari penjualan secara online 47 pcs dan offline 482 pcs. Untuk berat dari produk sendiri memiliki ukuran yang berbeda-beda yaitu sambel pecel dan bumbu gadogado dengan berat 100 gram, kripik lompong 120 gram dan 500 gram. Meskipun penjualan secara offline lebih banyak daripada online, admin Shopee Sambel Pecel dan Bumbu Gado-Gado Kuncit Kota Blitar selalu memberikan pelayanan yang terbaik untuk para konsumen. Hal ini dibuktikan dengan hasil wawancara

"Mungkin kalau dibilang mengalami kenaikan saat penjualan menggunaka marketplace shopee tidak ya, karena masyarakat masih cenderung lebih percaya untuk membeli dengan datang langsung ke tempat produksi maupun membeli dengan menghubungi langsung by WhatsApp". (NM..38)

Penggunaan Shopee di UMKM Sambel Pecel dan Bumbu Gado-Gado Kuncit Kota Blitar masih kurang maksimal, hal tersebut dikarenakan pemegang akun Shopee terlalu sibuk dengan penjualan offline. Selain itu, respon yang diberikan admin kepada konsumen yang hendak membeli cukup lama dengan presentase performa chat dengan konsumen memiliki presentase $87 \%$. Untuk update stok maupun diskripsi dari produk dilakukan oleh admin setiap 2 bulan sekali, hal ini dikarenakan admin kurang memegang handphone dan terlalu fokus untuk melayani pesanan offline. Foto yang digunakan di Shopee tampilan sangat baik dan bagus, hal ini akan menyebabkan konsumen menjadi lebih tertarik dengan produk yang ditawarkan. 
ISSN NO. (PRINT) 2598-0823, (ONLINE) 2598-2893

Tampilan Shopee Sambel Pecel Deskripsi Produk Sambel Pecel

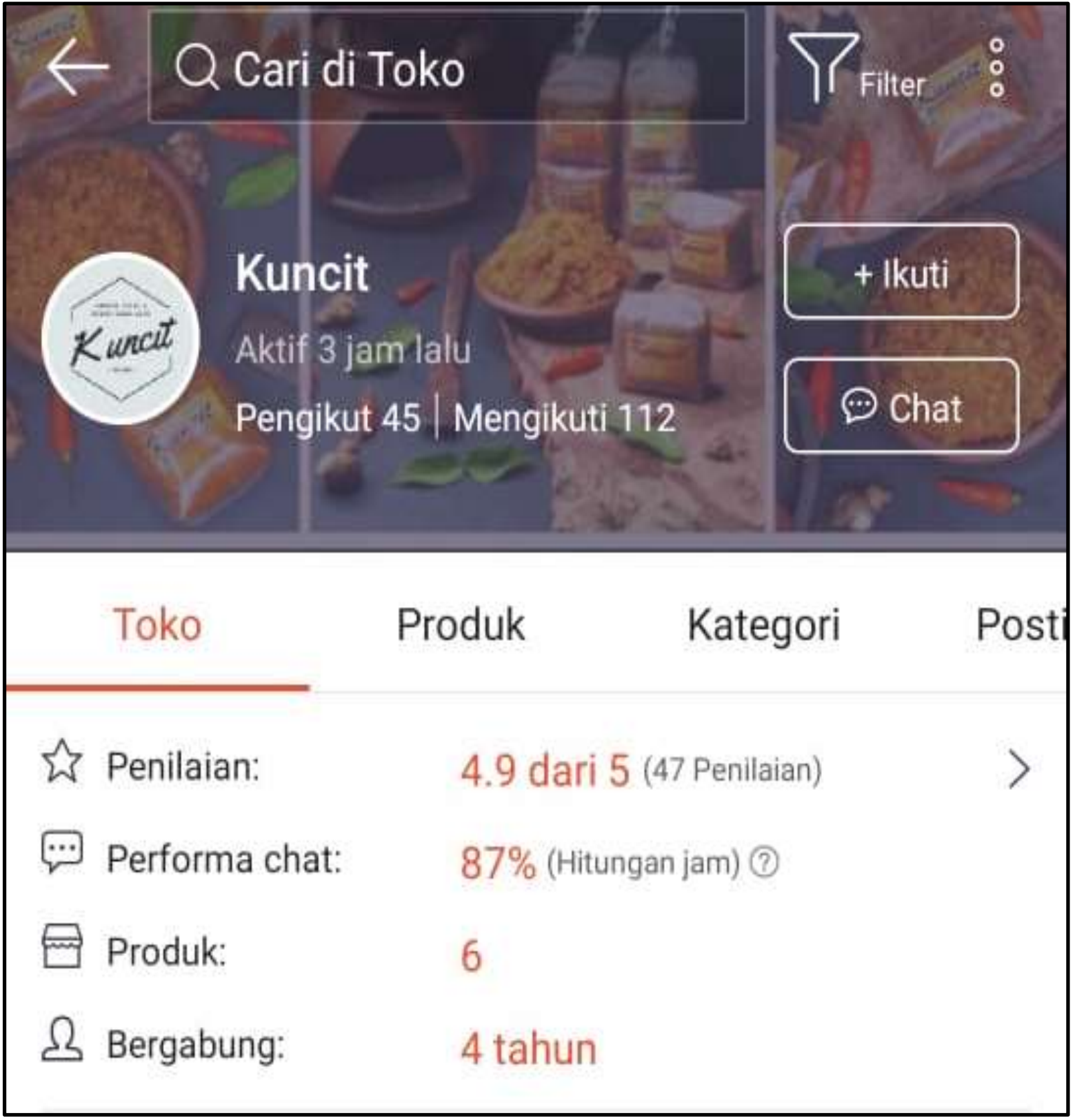

Gambar 1 Tampilan Shopee Sambel Pecel dan Bumbu Gado-Gado Kuncit Kota Blitar 
ISSN NO. (PRINT) 2598-0823, (ONLINE) 2598-2893

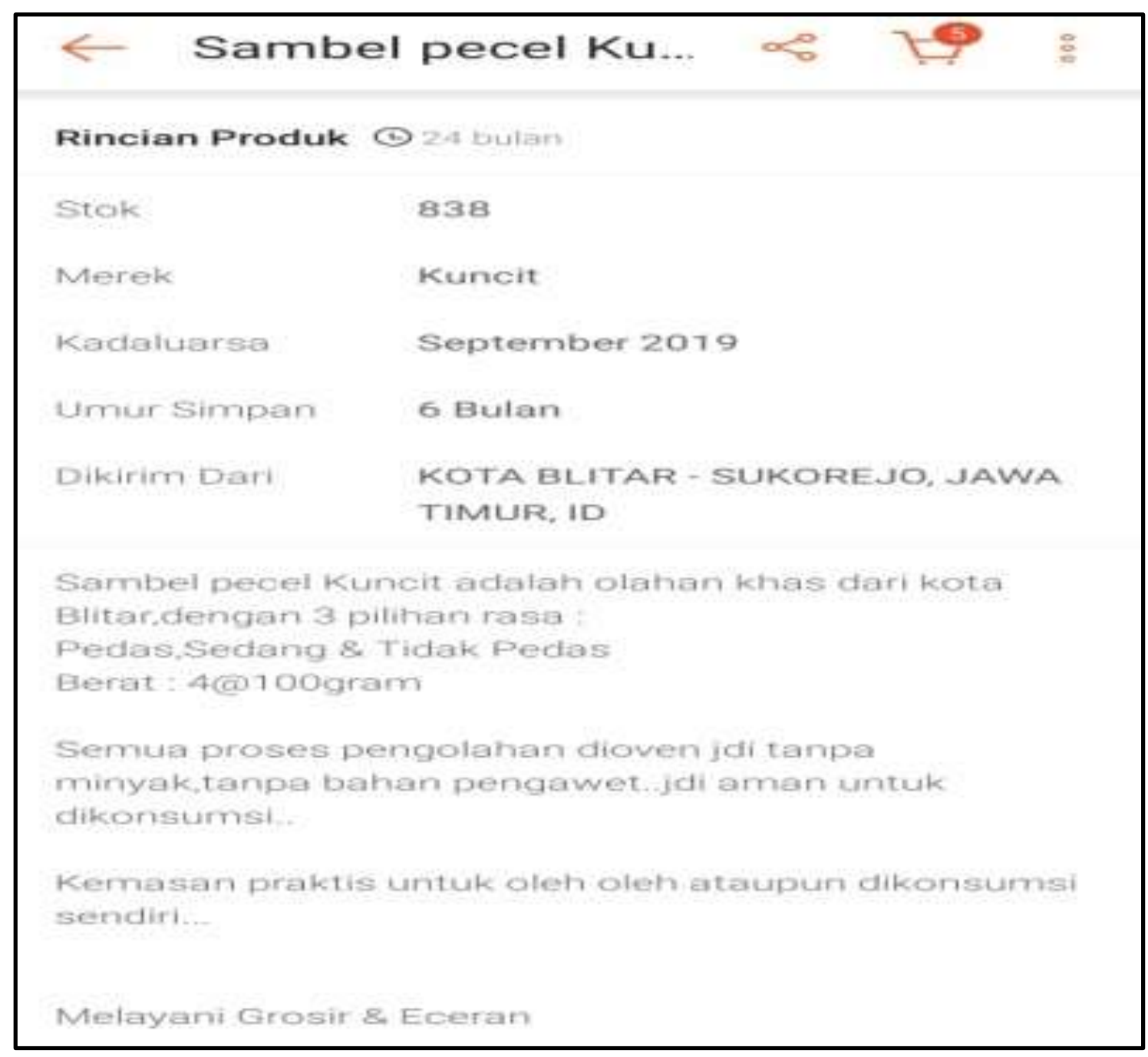

Gambar 2 Deskripsi Produk Sambel Pecel

\section{E. KESIMPULAN}

\section{Kesimpulan}

Marketplace Shopee yang digunakan di UMKM Sambel Pecel dan Bumbu GadoGado Kuncit Kota Blitar sebagai media promosi penjualan. Penggunaan marketplace Shopee ini bertujuan untuk mempermudah konsumen dalam membeli produk yang dijual di Shopee. Selain itu, konsumen tidak perlu datang langsung ke tempat produksi. Konsumen hanya perlu melakukan pemesanan produk melalui marketplace Shopee, dan barang yang sudah dipesan akan dikirim sesuai dengan alamat yang sudah diberikan melalui marketplace Shopee. Penggunaan marketplace Shopee sebagai media promosi penjualan di UMKM Sambel Pecel dan Bumbu Gado-Gado Kuncit Kota Blitar harus lebih ditingkatkan lagi supaya dapat melayani para konsumen atau pelanggan dengan lebih semaksimal mungkin agar daya beli konsumen dari hari ke hari mengalai peningkatan. 


\section{Saran}

Pemilik UMKM Sambel Pecel dan Bumbu Gado-Gado Kuncit Kota Blitar dapat memanfaatkan marketplace Shopee secara maksimal untuk meningkatkan penjualan secara online dan memaksimalkan pelayanan yang diberikan kepada para konsumen yang membeli melalui marketplace shopee. Perlu memaksimalkan dalam memanfaatkan seluruh fitur yang ada di Shopee baik fitur dari segi konsumen maupun penjual. Pemanfaatan ini dapat dilakukan dengan cara menambahkan produk baru maupun memberikan kelengkapan pada setiap keterangan dari produk. Serta menambah informasi mengenai fitur-fitur yang terdapat di marketplace shopee.

\section{DAFTAR PUSTAKA}

APJII. (2019). Penetrasi \& Profil Perilaku Pengguna Internet Indonesia Tahun 2018. Apjii, 51. Retrieved from www.apjii.or.id

As'ari, A. H. (2008). Peran UKM Terhadap Pertumbhan Ekonomi Indonesia. Jakarta: Harian Bisnis Indonesia.

Assauri, S. (2013). Manajemen Pemasaran. Jakarta. PT. Raja Grafindo Persada.

Kadim, A., Sunardi, N., Lesmana, R., \& Sutarman, A. (2019). Revitalisasi Fungsi Masjid Sebagai Pusat Penguatan Manajemen Peternak Sapi Rakyat melalui Lembaga Pemberdayaan Masyarakat Terpadu (LEMPERMADU).(Studi Kasus di Masjid Ainul Yaqin Kel. Jontlak, Kec. Praya, Kab. Lombok Tengah, Provinsi Nusa Tenggara Barat). Jurnal Abdi Masyarakat Humanis, 1(1).

Bachdar, S. (2018). Mengapa Shopee Jadi E-Commerce yang Paling Sering Diakses?No Title. Retrieved May 20, 2019, from https://marketeers.com/mengapa-Shopee-jadi-ecommerce-yang-paling-sering-diakses/

Bernadi, J. (2013). Aplikasi Sistem Informasi Penjualan Berbasis Web pada Toko Velg YQ. ComTech: Computer, Mathematics and Engineering Applications, 4(2), 731. https://doi.org/10.21512/comtech.v4i2.2504

Buchari, A. (2006). Manajemen Pemasaran dan Pemasaran Jasa. Bandung: Alfabeta.

Indonesia. (2008). Undang-Undang Nomor 11 Tahun 2008.

Kotler, P. 2006. (n.d.). Manajemen Pemasaran. Edisi ke dua belas jilid kedua. Dialih bahasakan oleh Benyamin Molan. (Jakarta: Penerbit Indeks, Ed.).

Kwahk, K. Y., \& Ge, X. (2012). The effects of social media on e-commerce: A perspective of social impact theory. Proceedings of the Annual Hawaii International Conference on System Sciences, 1814-1823. https://doi.org/10.1109/HICSS.2012.564

Latifah, N., Widayani, A., \& Normawati, R. A. (2020). Pengaruh Perceived Usefulness Dan Trust Terhadap Kepuasan Konsumen Pada E- Commerce Shopee. BISMA: Jurnal Bisnis Dan Manajemen, 14(1), 82. https://doi.org/10.19184/bisma.v14i1.13550

Lesmana, R. (2015). analisis strategi pemasaran untuk meningkatkan penjualan perumahan green river city bekasi (study kasus di pt. artha bangun pratama) (Doctoral 
dissertation, Universitas Pamulang).

Lesmana, R., \& Ayu, S. D. (2019). Pengaruh Kualitas Produk Dan Citra Merek Terhadap Keputusan Pembelian Kosmetik Wardah PT Paragon Tehnology And Innovation. Jurnal Pemasaran Kompetitif, 2(3), 59-72.

Lesmana, R., Sunardi, N., Hasbiyah, W., Tumanggor, M., \& Susanto, S. (2019). Manajemen Alokasi Dana Desa dalam Upaya dan Strategi Mewujudkan Desa Sejahtera Mandiri di Desa Cihambulu, Kec. Pabuaran, Kab. Subang, Jawa Barat. Jurnal Abdi Masyarakat Humanis, 1(1).

Lupiyoadi dan Hamdani. (2006). Manajemen Pemasaran jasa Edisi kedua. Salemba Empat: Jakarta.

Rahmati. (2009). Pemanfaatan E-commerce Dalam Bisnis Di Indonesia. Retrieved from http://citozcome.blogspot.com/2009/05/pemanfaatan-e-commerce-dalam-bisnisdi.html.

Siregar, R. R. (2010). Strategi Meningkatkan Persaingan Bisnis Perusahaan dengan Penerapan E-commerce. Retrieved from https://blog.trisakti.ac.id/riki/2010/03/12/strategi-meningkatkan-persaingan-bisnisperusahaan-dengan-penerapan-e-commerce/.

Sutrisno, J. (2011). Strategi Pengembangan Teknologi E-ommerce dengan Metode SWOT. Jurnal Telematika MKOM, 3(2), 44-50.

Sutarman, A., \& Lesmana, R. (2019, January). Analisis Keputusan Pembelian Konsumen dari Sisi Normtif dan Informatif Pada Supermarket Giant Pamulang, Tangerang Selatan. In PROCEEDINGS (Vol. 1, No. 1).

Sunardi, N., Lesmana, R., \& Tumanggor, M. (2018). Implementasi Manajemen Dalam Meningkatkan Iman Dan Taqwa Masyarakat Dusun Panyeredan, Cimanggu, Cisalak, Subang-Jawa Barat. Jurnal Pengabdian Dharma Laksana, 1(1), 131-140.

Usmara, U. (2008). Pemikiran Kreatif Pemasaran (Yogyakarta: Amara Books, Ed.).

Widayani, A., Astuti, E. S., \& Saifi, M. (2020). Competence and readiness of small and medium industries against of industrial revolution 4.0. IOP Conference Series: Earth and Environmental Science, 485(1), 0-7. https://doi.org/10.1088/1755$1315 / 485 / 1 / 012114$ 